\title{
STAT1-dependent and -independent pulmonary allergic and fibrogenic responses in mice after exposure to tangled versus rod-like multi-walled carbon nanotubes
}

Katherine S. Duke ${ }^{1}$, Alexia J. Taylor-Just ${ }^{1}$, Mark D. Ihrie ${ }^{1}$, Kelly A. Shipkowski', Elizabeth A. Thompson', Erinn C. Dandley ${ }^{2}$, Gregory N. Parsons ${ }^{2}$ and James C. Bonner ${ }^{1 *}$

\begin{abstract}
Background: Pulmonary toxicity of multi-walled carbon nanotubes (MWCNTs) is influenced by physicochemical characteristics and genetic susceptibility. We hypothesized that contrasting rigidities of tangled (t) versus rod-like ( $r$ ) MWCNTs would result in differing immunologic or fibrogenic responses in mice and that these responses would be exaggerated in transgenic mice lacking the signal transducer and activator of transcription-1 (STAT1), a susceptible mouse model of pulmonary fibrosis.

Methods: Male wild type $\left(\right.$ Stat $\left.^{+/+}\right)$and STAT1-deficient $\left(\right.$Stat $\left.^{-/-}\right)$mice were exposed to $4 \mathrm{mg} / \mathrm{kg}$ tMWCNTs, rMWCNTs, or vehicle alone via oropharyngeal aspiration and evaluated for inflammation at one and 21 days post-exposure via histopathology, differential cell counts, and cytokine levels in bronchoalveolar lavage fluid (BALF). Granuloma formation, mucous cell metaplasia, and airway fibrosis were evaluated by quantitative morphometry. Airway epithelial cell proliferation was assessed by bromodeoxyuridine (BrdU) incorporation. Cytokine protein levels in BALF and serum IgE levels were measured by ELISA. Lung protein Smad2/3 levels and activation were measured by Western blot. Lung mRNAs were measured by PCR.
\end{abstract}

Results: There was a 7-fold difference in rigidity between tMWCNTs and rMWCNTs as determined by static bending ratio. Both MWCNT types resulted in acute inflammation (neutrophils in BALF) after one-day post-exposure, yet only rMWCNTs resulted in chronic inflammation at 21 days as indicated by neutrophil influx and larger granulomas. Both MWCNTs induced BrdU uptake in airway epithelial cells, with the greatest proliferative response observed in rMWCNT-exposed mice after one-day. Only rMWCNTs induced mucous cell metaplasia, but this index was not different between genotypes. Stat ${ }^{-/-}$mice had higher levels of baseline serum IgE than Stat ${ }^{+/+}$mice. Greater airway fibrosis was observed with rMWCNTs compared to tMWCNTs, and exaggerated airway fibrosis was seen in the Stat $1^{-1-}$ mouse lungs with rMWCNTs but not tMWCNTs. Increased fibrosis correlated with elevated levels of TGF- $\beta 1$ protein levels in the BALF of Stat ${ }^{-1-}$ mice exposed to rMWCNTs and increased lung Smad2/3 phosphorylation.

(Continued on next page)

\footnotetext{
* Correspondence: jcbonner@ncsu.edu

'Toxicology Program, Department of Biological Sciences, North Carolina

State University, Campus Box 7633, Raleigh, NC 27695-7633, USA

Full list of author information is available at the end of the article
} 
(Continued from previous page)

Conclusions: Rigidity plays a key role in the toxicity of MWCNTs and results in increased inflammatory, immunologic, and fibrogenic effects in the lung. STAT1 is an important protective factor in the fibroproliferative response to rMWCNTs, regulating both induced TGF- $\beta 1$ production and Smad2/3 phosphorylation status. Therefore, both rigidity and genetic susceptibility should be major considerations for risk assessment of MWCNTs.

Keywords: Carbon nanotubes, Lung, Fibrosis, Growth factors, Transcription factors

\section{Background}

Carbon nanotubes (CNTs) are engineered nanomaterials that have structural similarities to asbestos because of their fiber-like shape and biopersistence [1-3]. While little is known about their adverse human health effects, rodent studies show multi-walled (MW) CNTs, like asbestos fibers, possess carcinogenic activity or cause pulmonary fibrosis after inhalation exposure or oropharyngeal aspiration [4-6]. Also reminiscent of asbestos fibers, MWCNTs reach the lung pleura after inhalation exposure in mice, where they irritate the pleural lining and cause pleural inflammation and subpleural fibrosis [7]. While some MWCNTs delivered to the lungs could translocate to other organs after pulmonary exposure, a significant fraction are biopersistent and remain in the lung and pleura up to a year after exposure in rodents, leading to chronic DNA damage and tissue fibrosis [8].

MWCNTs are a heterogeneous class of materials that can mediate different pathogenic responses in the lung, depending on their physicochemical properties. For instance, lung exposure to rod-like (r) MWCNTs can lead to allergic airway inflammation and mucous cell metaplasia, while exposure to tangled ( $t$ ) MWCNTs causes non-allergic lung inflammation with no mucous cell metaplasia [9-11]. Other properties of MWCNTs have been shown to play a role in their pulmonary toxicity (i.e. length, surface charge, residual metals) yet only a few studies comparing MWCNTs with contrasting rigidity have been conducted $[9,12]$. However, to our knowledge there are no studies that address genetic susceptibility to allergic or fibrogenic responses to MWCNTs with different rigidities. Examining the differences in allergic or fibroproliferative responses between tMWCNTs and rMWCNTs in genetically susceptible mouse models may elucidate differences in the fibrotic mechanisms of these MWCNTs.

Signal transducer and activator of transcription-1 (STAT1) is a transcription factor activated primarily by interferons (IFN- $\alpha,-\beta,-\gamma$ ), growth factors (e.g., epidermal growth factor (EGF), platelet derived growth factor (PDGF)), or by oxidative stress [13-15]. Upon activation, STAT1 is phosphorylated and homodimerizes with another STAT1 molecule, or heterodimerizes with other STAT family members (e.g. STAT2). Homodimers or heterodimers then translocate to the nucleus to bind a
DNA consensus sequence; each STAT1 dimer has a high affinity for its specific response element [16]. STAT1 serves as a protective response to injury, and is responsible for activating the transcription of key genes involved in cell viability, growth arrest, apoptosis, and differentiation $[17,18]$. Stat $1^{-/-}$mice exhibit increased fibrosis following exposure to the chemotherapeutic drug bleomycin compared to wild type $\left(\right.$ Stat $\left.^{+/+}\right)$mice, demonstrating that STAT1 is protective against fibrogenesis [19]. Also, ovalbumin sensitized Stat $^{-1-}$ mice that were subsequently challenged with tMWCNTs by oropharyngeal aspiration exhibit greater airway fibrosis than $\operatorname{Stat1}^{+/+}$mice, indicating that STAT1 plays a role in the immune response to tMWCNTs and allergens [11]. Moreover, fibroblasts isolated from lungs of Stat $^{-/-}$mice are more responsive in vitro to exogenous transforming growth factor (TGF)$\beta 1$, produce more collagen than Stat $^{+/+}$fibroblasts treated with TGF- $\beta 1$ and display an increased proliferative response in vitro to PDGF or EGF compared to $\operatorname{Stat1}_{1}^{+/+}$ fibroblasts [19].

It is unknown if STAT1 regulates differential fibrogenic or immune responses to tMWCNTs versus rMWCNTs. In the present study, we hypothesized that MWCNTs with different rigidities would produce different pulmonary immunologic and fibroproliferative responses and that these effects would be enhanced in Stat ${ }^{-/-}$mice. We investigated MWCNT-induced lung inflammation, allergic airway remodeling and fibrosis in Stat $^{+/+}$or Stat ${ }^{-/-}$ mice in vivo for one and 21 days after oropharyngeal aspiration of tMWCNTs or rMWCNTs. We observed that rMWCNTs caused more persistent lung inflammation, as well as airway mucous cell metaplasia and larger granulomas compared to tMWCNT exposure in wild type Stat $^{+/+}$mice. Interestingly, compared to Stat $^{+/+}$mice, Stat $^{-1-}$ mice exposed to rMWCNTs but not tMWCNTs exhibited enhanced airway fibrosis, airway epithelial cell proliferation, exaggerated serum IgE, increased levels of lung TGF- $\beta 1$ and increased activation of the TGF- $\beta 1$ induced transcription factors, Smad2 and Smad3. The results from this study are important because they reveal an interaction between a physicochemical attribute (rigidity) and a genetic factor (STAT1) to further our understanding of susceptibility to pulmonary fibrogenesis and allergic immune responses. Moreover, we identify a novel mechanism of enhanced lung fibrogenesis in Stat $^{-/-}$mice 
induced by rMWCNTs that involves exaggerated TGF- $\beta 1$ production and Smad2/3 activation.

\section{Results}

\section{Characterization of MWCNT rigidity}

Both tMWCNTs and rMWCNTs have been previously characterized for average residual metal content, length, and width and these data are summarized in Additional file $1[7,10]$. We further characterized these MWCNTs based on their rigidity using a measure of the bending ratio $\left(D_{b}\right)$ to approximate the static bending persistence length (SBPL) (i.e. the average length between each bend in the tube) (Fig. 1). TEM images clearly show that tMWCNTs are more tortuous compared to rMWCNTs (Fig. 1a). The rMWCNTs, with a $D_{b}$ of 0.8996 (stdev 0.2743) and a SBPL of 0.860, are about seven-fold more rigid than the tMWCNTs with a $D_{b}$ of 0.162 (stdev 0.3300) and a SBPL of 0.1191 (Fig. 1b).

\section{Macrophage uptake and inflammation}

Stat $^{+/+}$and Stat $^{-/-}$mice exposed to tMWCNTs or rMWCNTs by oropharyngeal aspiration (OPA) were

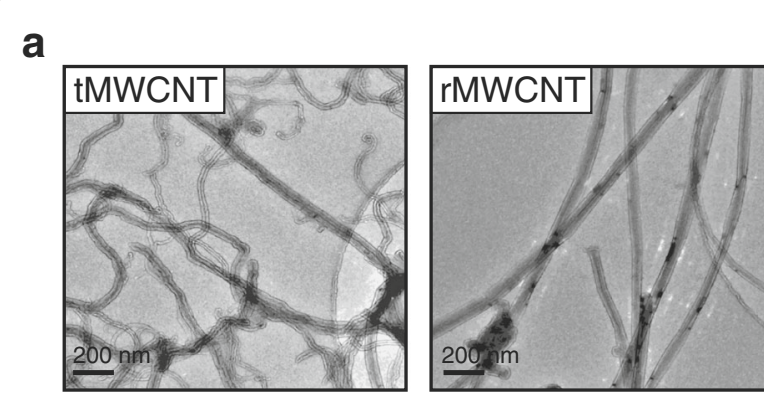

b

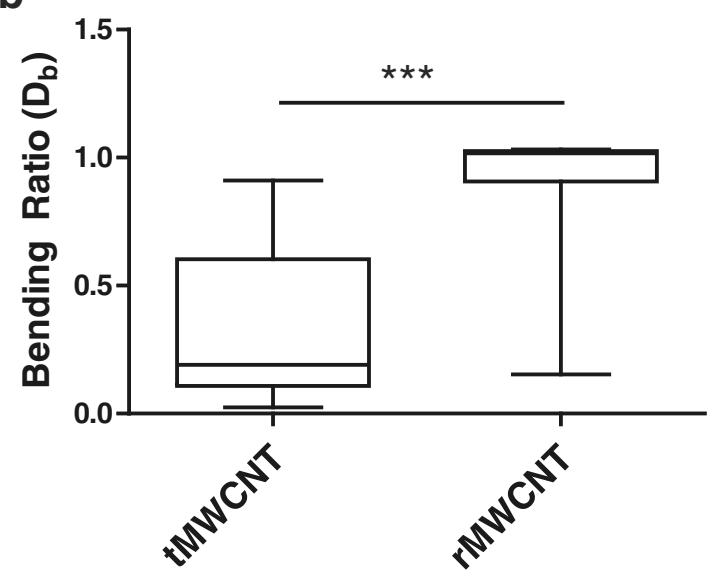

Fig. 1 Rigidity measurements of multi-walled carbon nanotubes (MWCNTs). a Transmission electron microscope (TEM) images of the tangled (t) MWCNTs and rod-like (r) MWCNTs showing the gross differences in rigidity taken at 10000X. b Box-and-whisker plots of the bending ratios $\left(D_{b}\right)$ of tMWCNTs and rMWCNTs $\left({ }^{* *} p<0.001\right.$ between means of MWCNT $D_{b}$ as determined by $t$-test) evaluated for changes in bronchoalveolar lavage fluid (BALF) inflammatory cells at one and 21 days postexposure according the protocol illustrated in Fig. 2a. BALF differential cell counts showed that both Stat $^{+/+}$ and Stat $^{-/-}$mice exhibited similar increases in infiltrating neutrophils at one-day post-exposure (Fig. 2b). Neutrophilic inflammation in the tMWCNT-treated mouse lungs resolved by 21 days, while neutrophilia in the lungs of rMWCNT-treated mice remained elevated at 21 days in both Stat $^{+/+}$and Stat1 ${ }^{-/-}$mice (Fig. 2b). The tMWCNTs are flexible and were completely engulfed by alveolar macrophages, while many of the rMWCNTs protruded from macrophages, indicating frustrated phagocytosis (Fig. 2c).

\section{MWCNT-induced granulomatous inflammation}

To ascertain if the Stat1 $^{+/+}$versus Stat1 $^{-/-}$genotypes determine differential chronic pulmonary inflammatory responses to each MWCNT type, the lungs of mice were analyzed for granuloma size and cellularity. Histopathologic analysis of lung tissue from MWCNT-treated mice showed alveolar parenchyma dispersion of MWCNTs and predominantly multifocal granulomatous inflammation and bronchitis (Fig. 3a). The granulomas observed following rMWCNT treatment contained a high number of neutrophils and eosinophils after 21 days. This is notable bearing in mind that classical granulomas consist of epithelioid, multinucleated giant cells, and a very sparse eosinophil or neutrophil presence (Fig. 3a insets). Only rMWCNT exposure resulted in bronchial inflammation and airway epithelial growth over the foreign body protrusions of rMWCNTs into the lumen of the airway, similar to some pathologic features of bronchiolitis obliterans. Quantitative analysis of granuloma number showed that at the same dose of $4 \mathrm{mg} / \mathrm{kg}$, both types of MWCNTs induced similar numbers of granulomas at 21 days with no differences between genotypes (Fig. 3b). While granulomas were observed in both tMWCNT and rMWCNT-treated mice after 21 days, granuloma size was significantly greater in rMWCNT-treated mice compared to tMWCNT-treated mice, although there were no significant differences between Stat $^{+++}$and Stat $^{-1-}$ mice (Fig. 3c). Together, these data demonstrate that rMWCNTs caused a more severe chronic inflammatory state in the lung, resulting in larger granuloma formations and that this inflammatory response was STAT1independent.

\section{Airway epithelial cell proliferation after MWCNT exposure} To determine if tMWCNTs or rMWCNTs caused lung cell proliferation, mice were injected i.p. with BrdU onehour prior to euthanasia and incorporation of BrdU into nuclei was visualized by immunohistochemistry (Fig. 4a). Vehicle treatment did not cause a significant increase in 
a

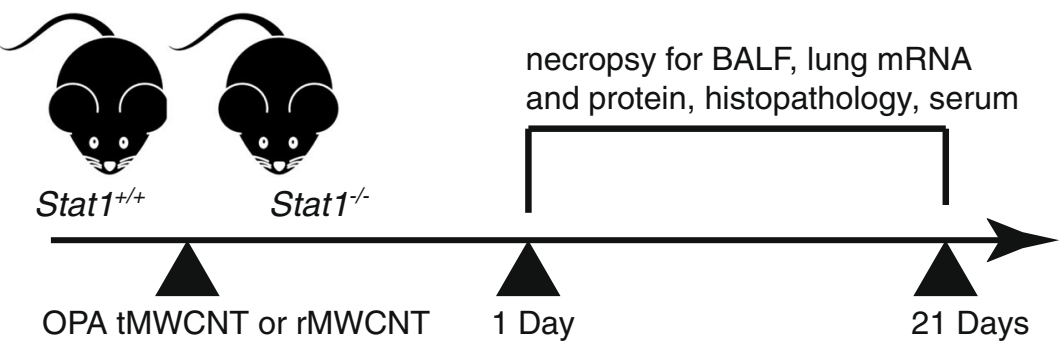

b
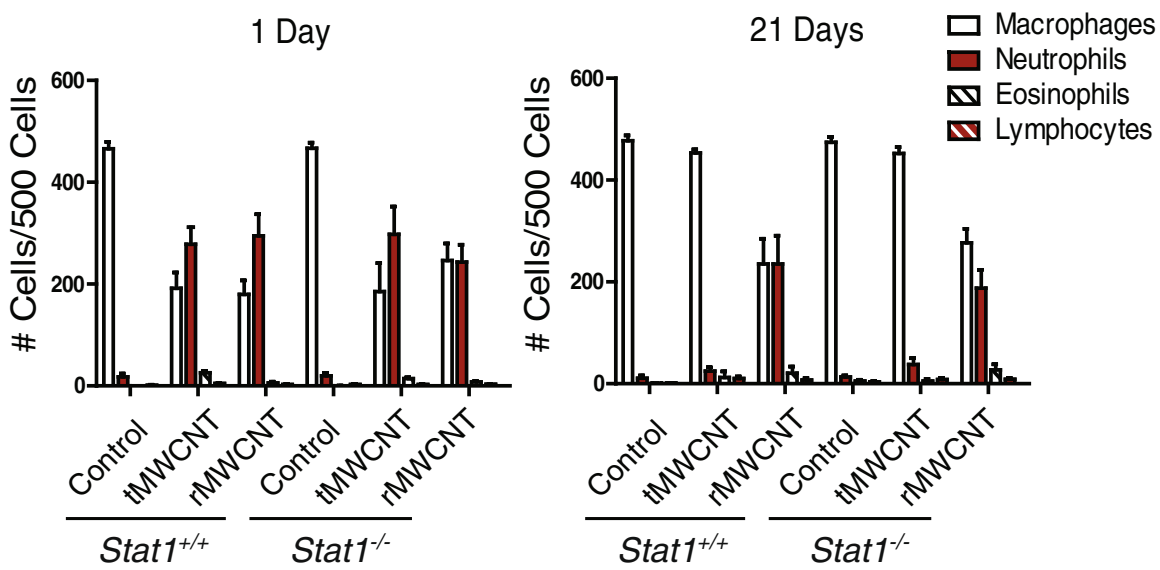

C
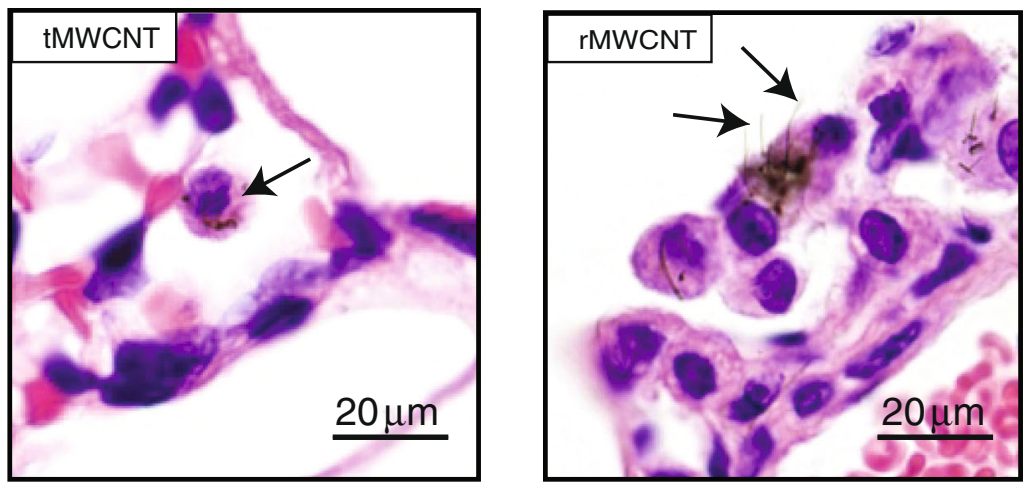

Fig. 2 Acute pulmonary response after oropharyngeal aspiration (OPA) to t- or r-MWCNTs. a Illustration of experimental design. b Differential cell counts quantified from Cytospins of BALF from Stat ${ }^{+/+}$and Stat $7^{-1-}$ mice exposed to tMWCNTs or rMWCNTs. $\mathbf{c}$ Hematoxylin and eosin-stained (H\&E) lung sections from mice treated with tMWCNTs or rMWCNTs at one-day post-exposure showing uptake of tMWCNTs and rMWCNTs by alveolar macrophages (arrows). Note frustrated phagocytosis of rMWCNTs but not tMWCNTs by macrophages

BrdU uptake in Stat $^{+/+}$or Stat $1^{-/-}$mice at either one or 21 days $(<1 \%$ BrdU-positive cells in airways). Both tMWCNTs and rMWCNTs caused a modest and similar increase in BrdU uptake in the airway epithelium of Stat $^{+/+}$mice at one-day post-exposure $(5-10 \%$ BrdUpositive cells in airways). In contrast, rMWCNTs caused a significant increase in BrdU uptake in the airway epithelium of Stat $^{-/-}$mice (10-15\% BrdU-positive cells in airways) compared to tMWCNT treatment or vehicle at one-day post-exposure in $\mathrm{Stat}^{-/-}$mouse lungs, but there was no significant difference compared to Stat $^{+/+}$ MWCNT-exposed mouse lungs (Fig. 4b). At 21 days postexposure BrdU uptake in response to MWCNTs had subsided to $\sim 5 \%$ BrdU-positive cells or less, although there was a significant increase in proliferation of the airway epithelial cells in the lungs of both $\operatorname{Stat1}^{+/+}$and $\mathrm{Stat1}^{-/-}$ mice treated with rMWCNTs compared to tMWCNTs or vehicle control (Fig. 4b). 


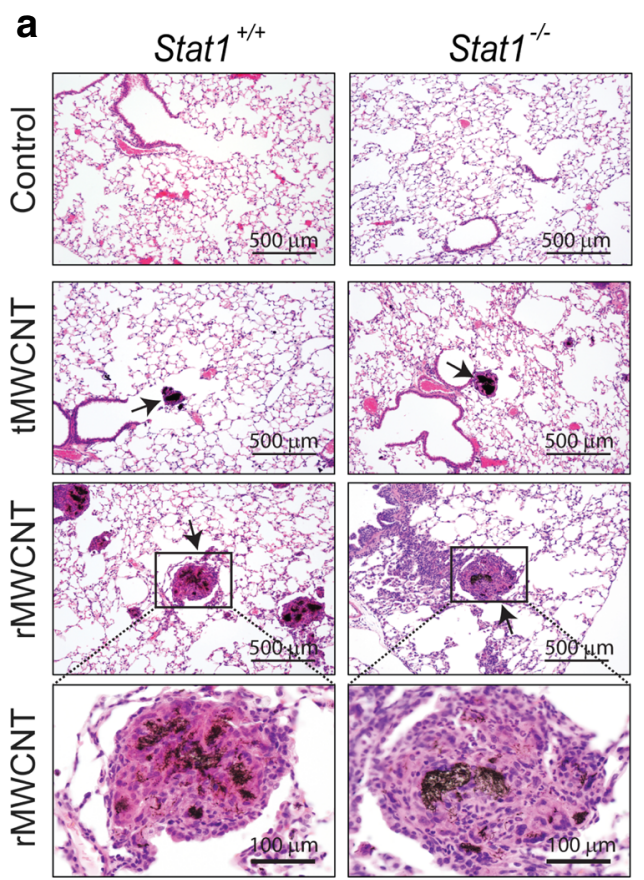

b
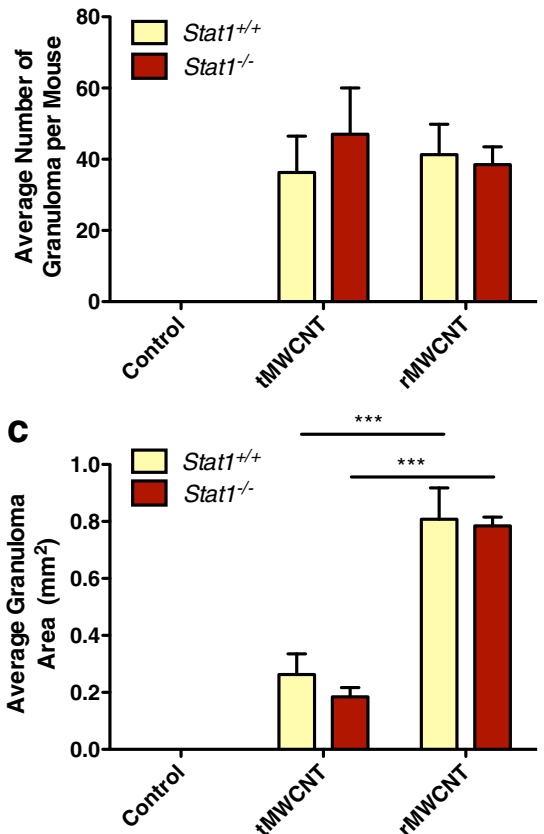

Fig. 3 Granuloma development at 21 days post-exposure to tMWCNTs or rMWCNTs. a Representative H\&E photomicrographs of 21 day control, tMWCNT or rMWCNT-exposed mouse airways showing granulomas (arrows) taken at 200X magnification (scale bars equal $500 \mu \mathrm{m}$ ). Insets of rMWCNT granulomas (Scale bars equal $100 \mu \mathrm{m}$ ) taken at 400X magnification. b Average number of granulomas per 3 lung sections per mouse. c Average size of granulomas measured by quantitative morphometry as described in Methods. (*** $p<0.001$ between tMWCNTs and rMWCNTs)

\section{MWCNT-induced mucous cell Metaplasia}

We observed airway mucous cell metaplasia in the lungs of both Stat1 $^{+/+}$and Stat $^{-/-}$mice exposed to rMWCNTs at 21 days but not in mice treated with tMWCNTs (Fig. 5a). Mucous cell metaplasia in response to rMWCNTs was evident by the appearance of AB-PAS-positive goblet cells in the airway epithelium. Quantitative morphometry of all airways sectioned from each mouse revealed a similar increase in AB-PAS goblet cells induced by rMWCNTs in both Stat $^{+/+}$and Stat1 ${ }^{-/-}$mice (Fig. 5b).

\section{MWCNT-induced serum IgE and allergic cytokine pulmonary mRNA levels}

There was an increased amount of basal IgE levels in the serum of Stat $^{-/-}$mice compared to Stat1 ${ }^{+/+}$mice at one and 21 days after exposure to the pluronic vehicle control (Fig. 6). Exposure to tMWCNTs did not increase serum IgE levels in either Stat $^{+/+}$or Stat1 $^{-/-}$mice at either time point (Fig. 6). In contrast, rMWCNTs significantly increased levels of serum IgE at 21 days after exposure to rMWCNTs in Stat $^{-1-}$ mice as compared to Stat $^{-/}$vehicle control (Fig. 6b). There was a slight increase in lung IL-4 mRNA expression at one-day postexposure to rMWCNTs in the Stat $^{-/-}$mice compared to Stat $^{+/+}$mice (Additional file 2A). This difference abated by 21 days post-exposure (Additional file 2B). IL13 mRNA levels were not significantly changed by exposure to tMWCNTs or rMWCNTs in either genotype at one or 21 days (Additional file $2 \mathrm{C}$ and $\mathrm{D}$ ).

\section{MWCNT-induced pulmonary fibrosis}

Lung and airway fibrosis was quantified by morphometric analysis of Masson's trichrome-stained slides and soluble collagen content from lung protein lysates. Histopathologic evaluation revealed that fibrosis was limited primarily to airways and induced by rMWCNTs but not tMWCNTs. Quantitative morphometry of airway fibrosis to generate area/perimeter ratio measurements indicated significant focal peribronchiolar collagen deposition after exposure to rMWCNTs but not tMWCNTs in the lungs of Stat1 ${ }^{+/+}$ and Stat $^{-/-}$mice (Fig. 7a-b). Moreover, Stat ${ }^{-/-}$mice had significantly more airway fibrosis as compared to Stat $^{+++}$mice 21 days after exposure to rMWCNTs (Fig. 7b). Despite the regional increase in airway fibrosis caused by rMWCNTs, there was not a significant difference in total lung collagen at 21 days post-exposure among treatment groups or genotypes as measured by Sircol assay (Additional file 3) or hydroxyproline assay (data not shown).

\section{MWCNT-induced expression of TGF- $\beta 1$ and other Profi- brogenic cytokines}

TGF- $\beta 1$, a primary mediator of fibrosis, was measured at the protein level by ELISA in the BALF of mice. TGF- $\beta 1$ 
a
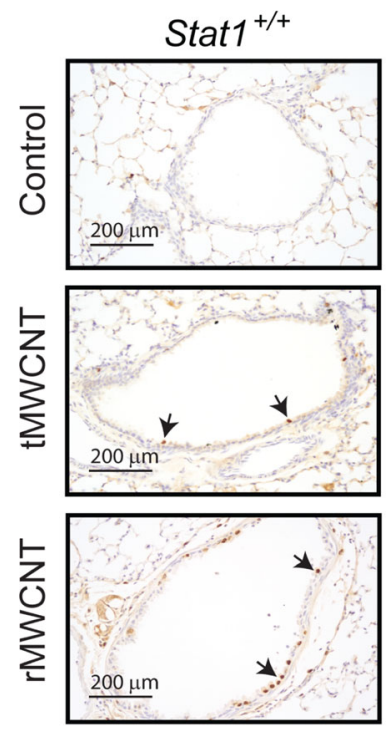

b

1 Day

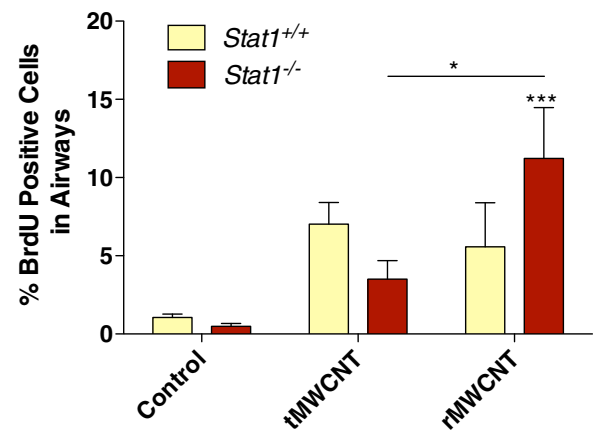

Stat $1^{-1}$
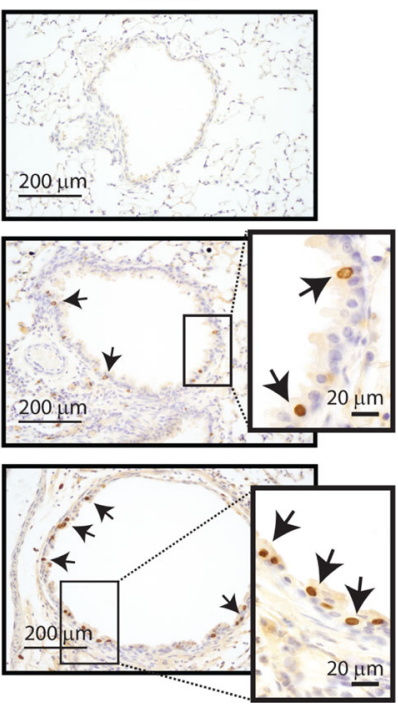

C

21 Days

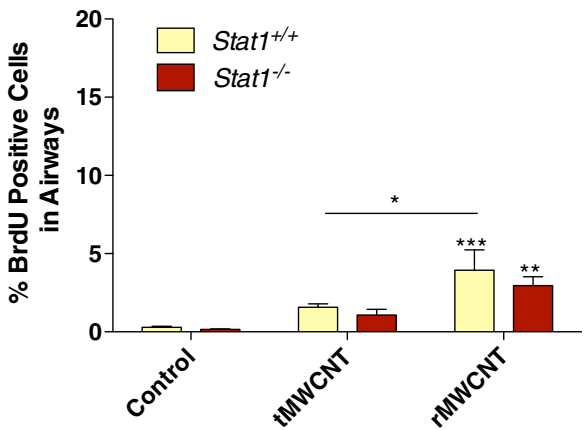

Fig. 4 Airway epithelial cell proliferation in Stat $1^{+/+}$and $\mathrm{Stat}^{-1 /}$ mice after one and 21 days exposure to MWCNTs. a Bromodeoxyuridine (BrdU) immunostaining at one-day post-exposure to tMWCNTs or rMWCNTs showing BrdU-positive brown nuclei of proliferating cells (arrows). b Quantification of BrdU positive cells per airway after one and $\mathbf{c} 21$ days of exposure. $\left({ }^{* * *} p<0.001\right.$ compared to control; ${ }^{*} p<0.05$ between tMWCNTs and rMWCNTs)

was significantly increased by rMWCNT-treatment in Stat $1^{+/+}$mouse BALF at 21 days, and further significantly increased in the BALF of Stat1 ${ }^{-1-}$ mice that were treated with rMWCNTs (Fig. 8a). In contrast, TGF- $\beta 1$ was not increased in the BALF from tMWCNT-treated mice at one or 21 days post-exposure (Fig. $8 \mathrm{a})$. TGF- $\beta 1$ was not detectable in the BALF from any of the treatment groups or genotypes at one-day post-exposure (data not shown). Several other cytokines implicated in fibrogenesis, including osteopontin (OPN), plateletderived growth factor (PDGF), and interleukin-1 $\beta$ (IL$1 \beta)$, were also measured at the protein level in BALF or at the mRNA level in lung tissue. The BALF from rMWCNT-exposed mice contained significantly more OPN protein after the one-day exposure, while the BALF from tMWCNT-treated mice contain significantly more OPN 21 days after exposure (Additional file 4A-B). Induction of OPN by MWCNTs was not significantly different between Stat1 $^{+/+}$and Stat $^{-/-}$mice. An ELISA was also conducted to measure the interleukin-1 $\beta$ (IL-1 $\beta$ ) in BALF. However, no significant differences in secreted IL-1 $\beta$ protein were observed among treatment groups or genotypes (data not shown). The expression of two PDGF isoforms (PDGF-A and PDGF-B) were measured from lung tissue by Taqman qRT-PCR. While there was a trend for higher levels of PDGF-A and PDGF-B mRNA in the lung tissue from Stat $^{-/-}$mice, these increased levels were not significant (Additional file 5).

\section{Effect of MWCNTs on TGF- $\beta 1$ signaling molecules}

Because changes in TGF- $\beta 1$ protein levels in BALF closely matched the pathologic changes in airway fibrosis in Stat1 $^{+/+}$and Stat $^{-/-}$mice exposed to rMWCNTs, we sought to investigate components of the TGF- $\beta 1$ signaling pathway. Total protein lysates were extracted from snap frozen lung tissue and separated by SDS-PAGE 


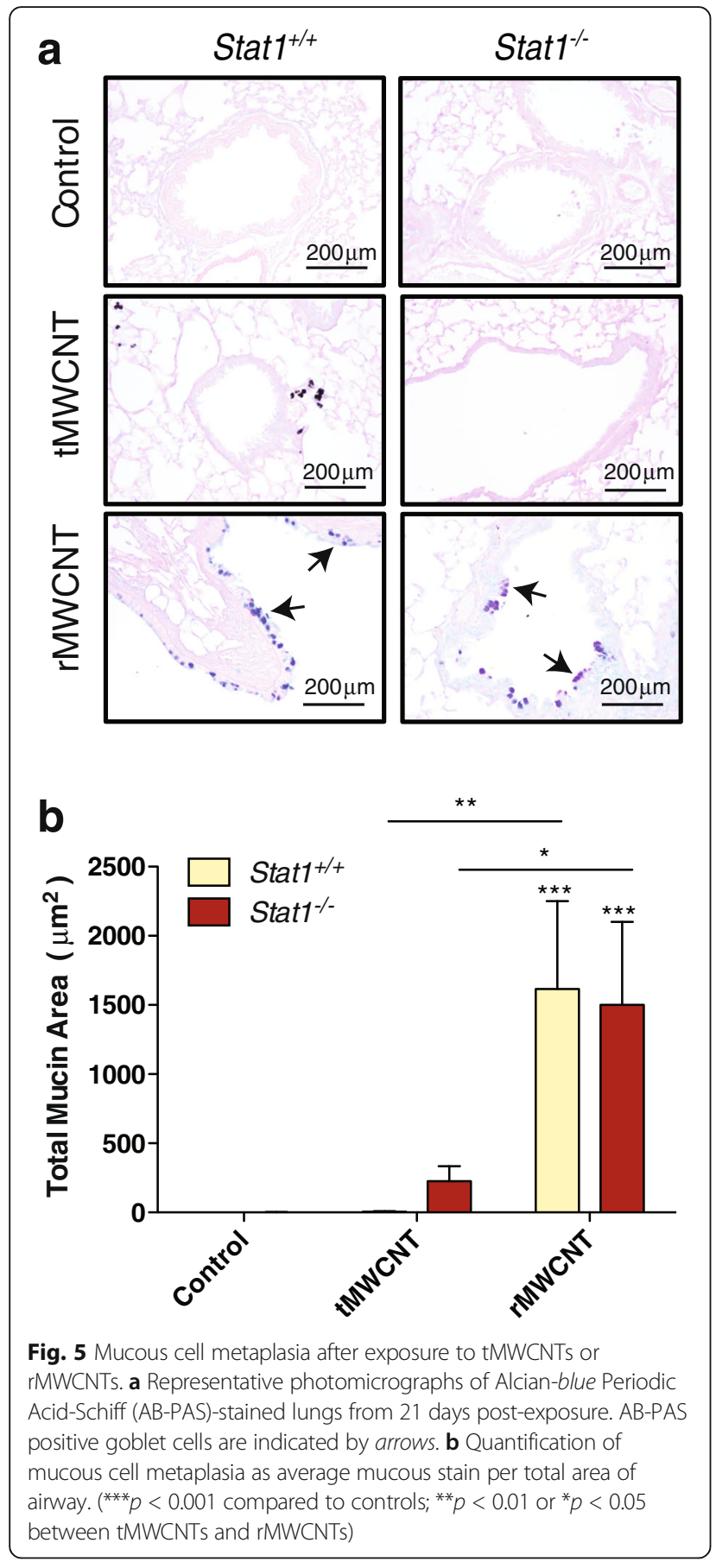

followed by Western blot analysis using antibodies specific for TGF- $\beta 1$ Receptor II (TGF- $\beta$ RII), phosphorylated $\operatorname{Smad} 2 / 3(\mathrm{p}-\mathrm{Smad} 2 / 3)$ and total $\operatorname{Smad} 2 / 3$. $\beta$-actin was measured as a constitutively expressed protein and used to normalize for densitometry of visualized protein bands (Fig. 8b). The levels of TGF$\beta R I I$ remained unchanged in both genotypes following either treatment (data not shown). Overall levels of Smad2/3 were increased with rMWCNT exposure

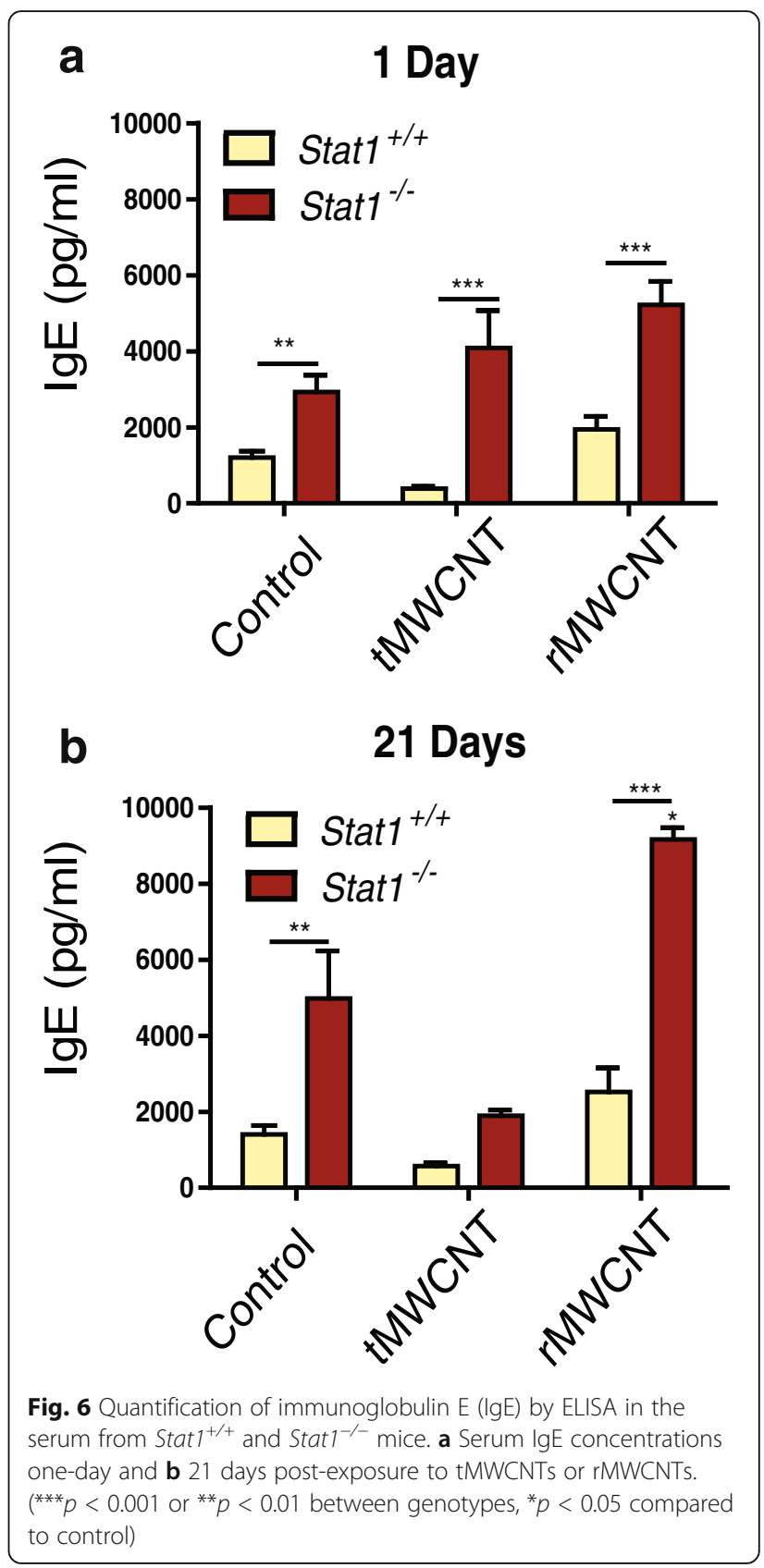

and decreased with tMWCNT exposure, but not significantly different among genotypes (Fig. 8c). The ratio of $\mathrm{p}-\mathrm{Smad} 2 / 3$ to total $\operatorname{Smad} 2 / 3$ levels displays a higher trend of Smad2/3 activation in Stat $^{-/-}$mouse lungs compared to $\operatorname{Stat1}^{+/+}$with no significant difference between exposures (Fig. 8d). The transcriptional targets of activated p-Smad2/3, Col1a1 and Col1a2, mirror this trend as measured via Taqman qRT-PCR from whole lung mRNA, however the transcription levels of these collagen mRNAs did not change with treatment (Additional file 6). 

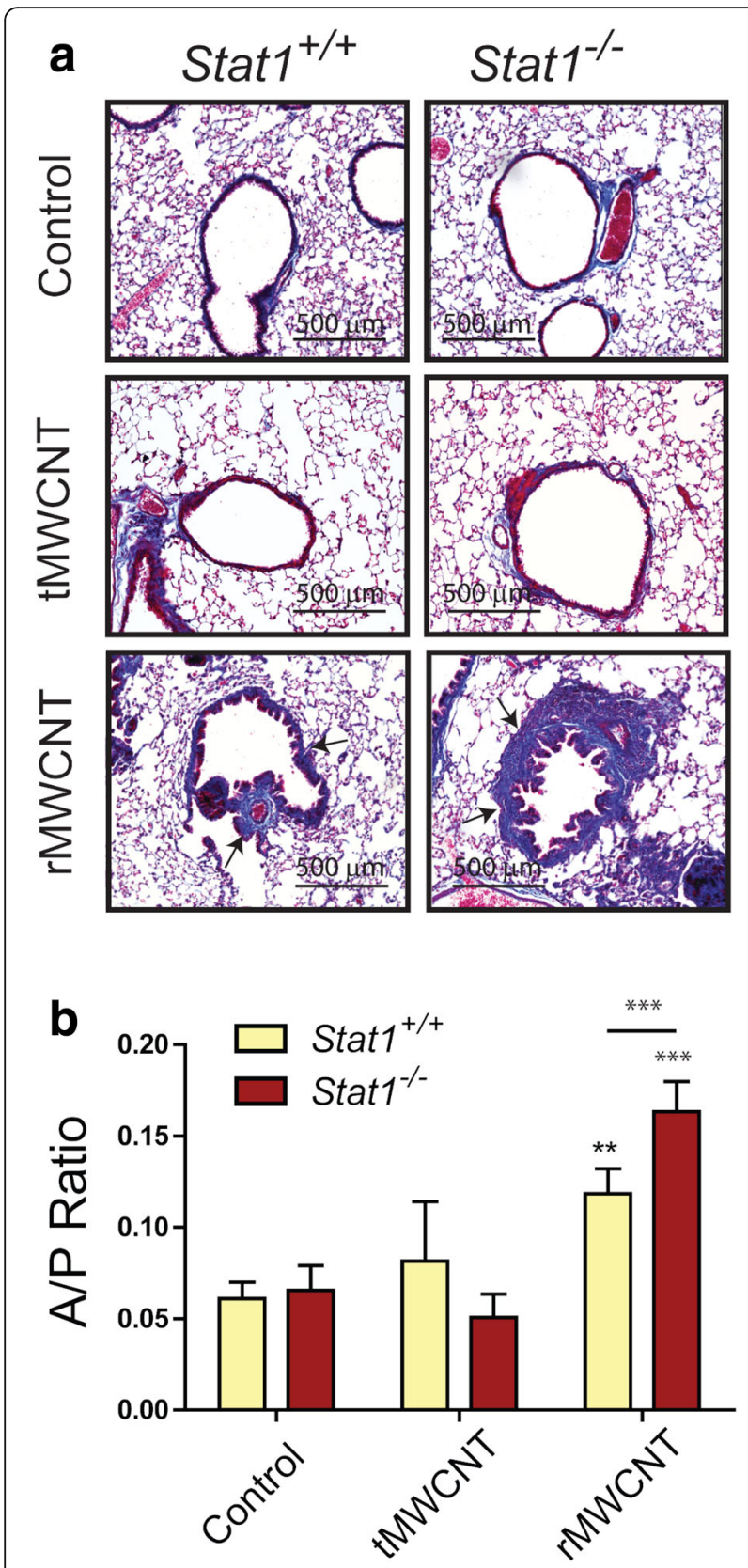

Fig. 7 Airway fibrosis in Stat ${ }^{+/+}$and Stat $^{-/-}$mice exposed to tMWCNTs or rMWCNTs. a Representative photomicrographs taken at 200X magnification of Massons trichrome-stained lung sections showing collagen deposition around airways (arrows) in mouse lungs at 21 days post-exposure. Connective tissue (e.g. collagen) stains blue. Scale bars equal $500 \mu \mathrm{m}$. b Area to perimeter (A/P) ratios of mouse lung airway thickness at 21 days post-exposure. ${ }^{* * *} p<0.001$ or ${ }^{* *} p<0.01$ compared to control; ${ }^{* *} p<0.001$ between tMWCNTs and rMWCNTs)

\section{Discussion}

In this study, we investigated the pulmonary allergic, inflammatory and fibrogenic responses of Stat $^{+/+}$and Stat $1^{-/-}$mice to rod-like (r) or tangled (t) MWCNTs delivered by oropharyngeal aspiration. Since significant differences were observed in airway fibrogenic responses to rMWCNTs between Stat ${ }^{+/+}$and Stat $^{-/-}$mice, we further investigated a mechanism of enhanced fibrosis involving induction of TGF- $\beta 1$ and Smad2/3 transcription factors that mediate collagen production. Previous studies by other investigators have focused on differential inflammatory, fibrotic, allergic, or carcinogenic effects of $\mathrm{r}$ - versus t-MWCNTs in wild type mice [5, 9, 20-22]. However, to our knowledge this is the first time MWCNT rigidity has been quantified and differential allergic or fibrogenic responses to rMWCNTs versus tMWCNTs have been studied in $S t a t 1^{-/-}$mice, or any other susceptible transgenic mouse strain.

We previously reported that Stat $1^{-/-}$mice are susceptible to lung fibrosis caused by oropharyngeal aspiration of bleomycin or by co-exposure to MWCNTs and ovalbumin allergen $[11,19]$. In the latter study, tMWCNTs in the absence of allergen did not cause significant pulmonary fibrosis in $S t a t 1^{-/-}$or $\operatorname{Stat}^{+/+}$mice, an observation confirmed in the current study. In the present study, we observed that rMWCNTs but not tMWCNTs significantly increased airway fibrosis in the lungs of Stat $1^{+/+}$mice and fibrosis was further increased in Stat $1^{-1-}$ mice focally around airways. Similarly, rMWCNTs but not tMWCNTs significantly increased TGF- $\beta 1$ levels in the BALF of $S t a t 1^{+/+}$mice and further increased TGF- $\beta 1$ in $S t a t 1^{-/-}$mice after 21 days. However, the increase in TGF- $\beta 1$ did not correlate with increased total lung collagen mRNAs (Col1a1 and Col1a2) at one or 21 days post-exposure, indicating that a regional increase in airway fibrosis might not be detectable by assays that measure total lung collagen mRNA or protein levels (i.e., Sircol and hydroxyproline assays). In addition, rMWCNTs but not tMWCNTs induced total lung levels of Smad2/3 and greater Smad2/3 phosphorylation was observed in Stat $^{-/-}$mouse lungs compared to Stat ${ }^{+/+}$ mouse lungs. Therefore, our findings suggest that STAT1 regulates fibrosis through suppressing TGF- $\beta 1$ production and decreasing Smad2/3 phosphorylation status. No changes were observed in TGF- $\beta$ RII protein levels in the lungs of $\operatorname{Stat1}^{+/+}$or Stat ${ }^{-/-}$mice treated with or without MWCNTs. These findings suggest that increased airway fibrosis in the lungs of Stat $1^{-/-}$mice exposed to rMWCNTs is mediated by increased levels of TGF- $\beta 1$ in the BALF as well as increased Smad2/3 activation in lung tissue. A proposed mechanism illustrating the role of STAT1 in suppressing TGF- $\beta 1$ and Smad2/3 activation in rMWCNT-induced airway fibrosis is shown in Fig. 9.

In the present study, we showed that rMWCNTs or tMWCNTs caused similar acute neutrophilic inflammation in the lungs of either $\operatorname{Stat}^{-/-}$or Stat $1^{+/+}$mice at one-day post-exposure, although only rMWCNTs caused elevated neutrophil counts in the BALF of mice at 21 days (Fig. 2) along with pulmonary fibrosis at 21 days 


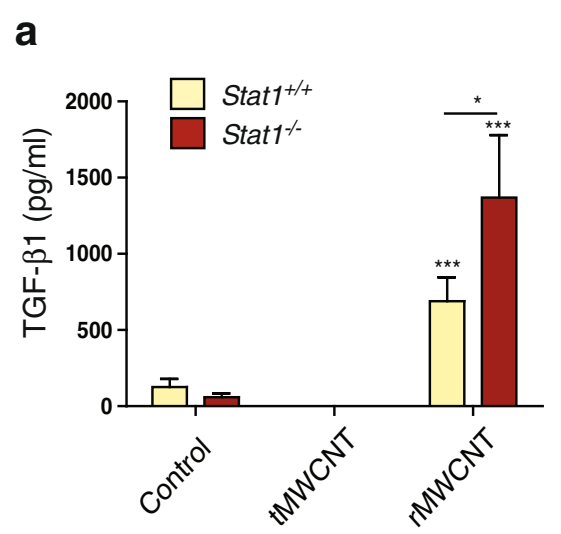

C

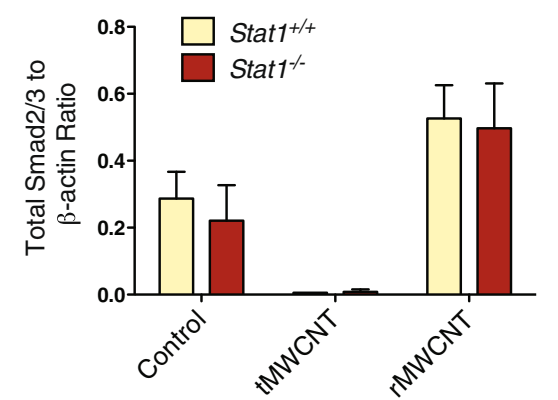

b

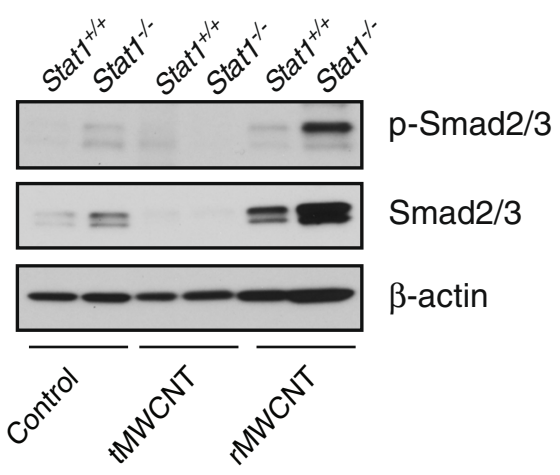

d

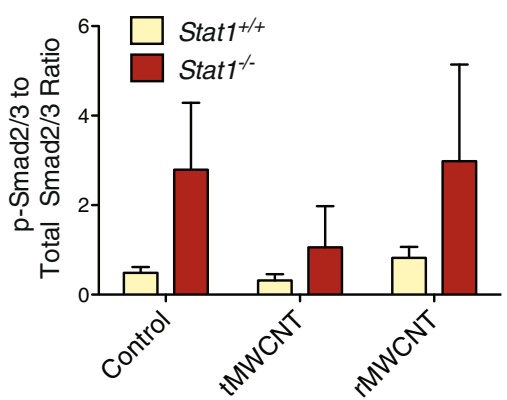

Fig. 8 TGF- $\beta 1$ protein levels and p-Smad2/3 levels in lung tissue from Stat $1^{+/+}$and Stat ${ }^{-/-}$mice after 21 days of exposure to tMWCNTs or rMWCNTS. a TGF- $\beta 1$ protein in BALF was measured by ELISA ( ${ }^{* * *} p<0.001$ compared to controls; ${ }^{*} p<0.05$ between genotypes). b Representative Western blot showing p-Smad2/3 and total Smad2/3 protein levels in lung tissue. c Densitometry of total Smad2/3 levels normalized to $\beta$-actin levels. $\mathbf{d}$ Quantification of the ratio of $\mathrm{p}$-Smad2/3 to total Smad2/3 densitometry levels relative to $\beta$-actin

(Fig. 7). The similar acute inflammatory response seen with rMWCNTs and tMWCNTs with fibrosis caused only by rMWCNTs was not surprising as previous studies have shown that acute inflammation is not a prerequisite for fibrogenesis. For example, the glucocorticoid dexamethasone dramatically reduces acute silica-induced lung inflammation in NMRI mice but did not reduce silicainduced fibrosis in these mice, indicating that the development of silica-induced lung fibrosis was uncoupled from acute inflammatory lung responses [23]. In another study, MWCNT-induced acute neutrophilic lung inflammation was ablated in IL-1 receptor knock-out (IL-1 $\mathrm{R}^{-/-}$) mice, although $\mathrm{IL}-1 \mathrm{R}^{-/-}$mice developed significantly greater MWCNT-induced lung fibrosis compared to wild type mice [24]. Therefore, our findings indicating that acute inflammation is not a prerequisite for fibrosis is consistent with other reports of particle-induced fibrosis. However, it is possible that chronic sustained neutrophilic inflammation seen in our study could play a role in modifying the fibrotic response to MWCNTs.

The susceptibility of Stat $^{-1-}$ mice to pulmonary fibrosis is consistent with the well-established function of STAT1 as a primary growth inhibitory signaling pathway for interferons $[17,18]$. For example, STAT1 specifically interacts with cyclin D1 and CDK4 to mediate cell cycle arrest in a human fibrosarcoma cell line after treatment with interferon (IFN) $-\gamma$ [25]. We originally reported that Stat $^{-/-}$mouse lung fibroblasts (MLFs) have enhanced proliferative responses to PDGF or EGF in vitro when co-treated with IFN- $\gamma$, whereas the proliferative response to these growth factors was inhibited by IFN- $\gamma$ in Stat ${ }^{+/+}$ MLFs [19]. The enhanced proliferative response of Stat ${ }^{-/-}$ MLFs was likely due to the fact that IFN- $\gamma$ activates other pathways independent of STAT1 (e.g., mitogen activated protein kinases (MAPKs) and protein kinase B (Akt)) [17]. Therefore, in the absence of STAT1, IFN- $\gamma$ signaling can participate in growth promoting pathways otherwise kept in check by the presence of STAT1.

In addition to suppression of fibroblast growth, another anti-fibrotic mechanism of STAT1 involves inhibition of TGF- $\beta 1$ signaling. We previously established that Stat $1^{-/-}$ MLFs express higher levels of collagen mRNAs and produce more collagen protein than Stat $^{+/+}$MLFs when stimulated with TGF- $\beta 1$ [11]. STAT1 has also been shown to be a negative regulator of hepatic fibrosis, where IFN- $\gamma$ treatment of Stat $^{+/+}$mice did not result in fibrosis while the same treatment of Stat $1^{-/-}$mice resulted in increased hepatic fibrosis and accelerated TGF- $\beta 1 /$ Smad signaling [26]. Here, we showed for the first time that Stat $^{-1-}$ mice have exaggerated levels of TGF- $\beta 1$ in the bronchoalveolar 


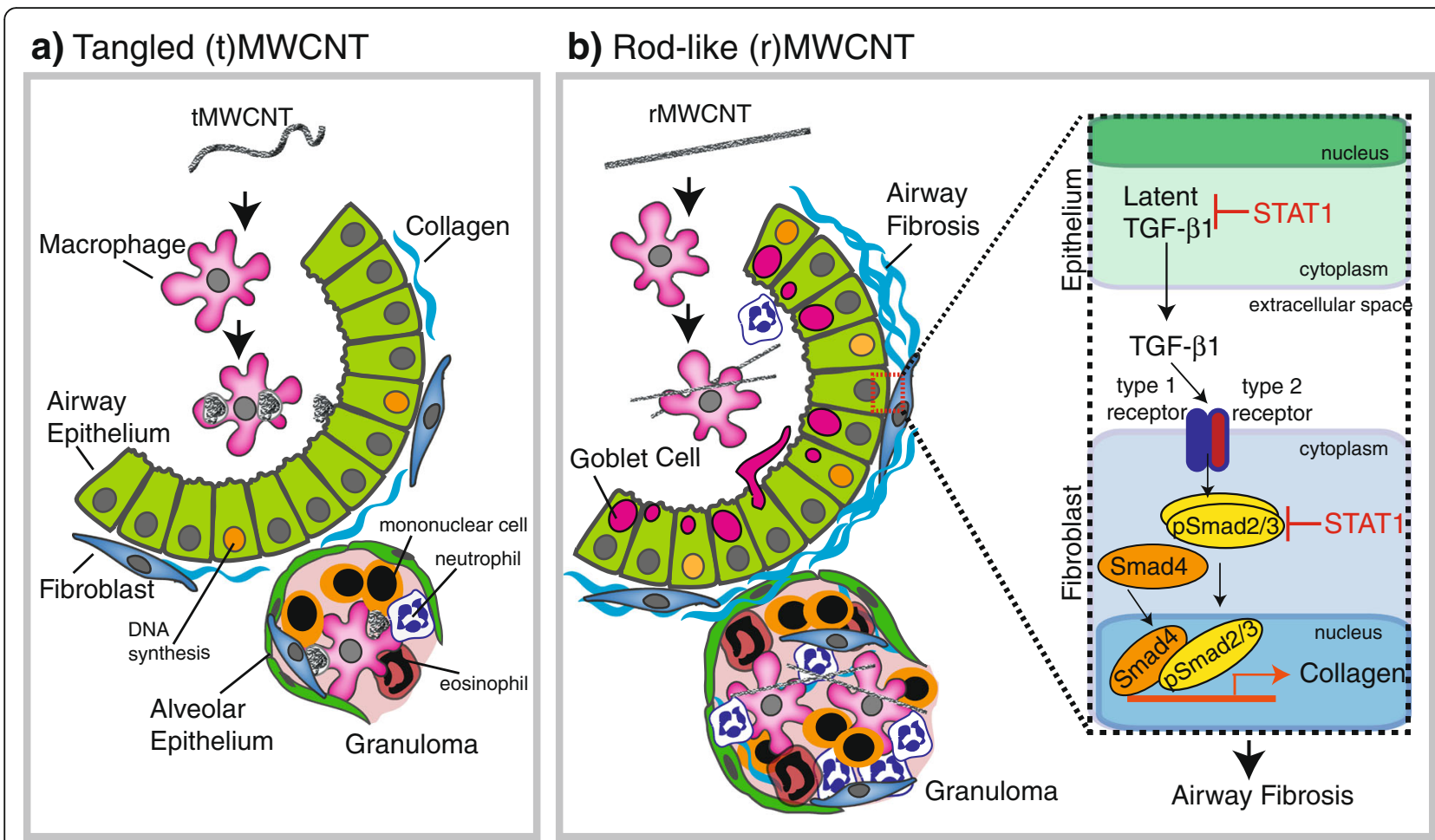

Fig. 9 Summary illustration depicting differential chronic lung immune and fibrotic responses at 21 days post-exposure to a tangled (t)MWCNTs or $\mathbf{b}$ Rod-like (r)MWCNTs. The inset in panel B highlights the postulated role of STAT1 in suppressing TGF- $\beta 1$ production by epithelial cells and Smad2/3 activation levels in fibroblasts

lavage fluid relative to Stat $^{+/+}$mice after exposure to rMWCNTs, demonstrating that STAT1 negatively regulates TGF- $\beta 1$ production and that rMWCNTs are more potent inducers of TGF- $\beta 1$ compared to tMWCNTs. We also established that $\mathrm{Smad} 2 / 3$ phosphorylation status was increased in Stat $^{-/-}$mice compared to Stat ${ }^{+/+}$mice. Collectively, these data suggest that STAT1 suppresses rMWCNT-induced fibrosis by suppressing TGF- $\beta 1$ production and intracellular Smad2/3 activation (Fig. 9). The mechanism of enhanced phosphorylation of Smad2/3 in Stat $1^{-1-}$ MLFs by rMWCNTs remains to be elucidated. However, others have shown that activated STAT1 homodimers upregulate SOCS1 and Smad7, thereby inhibiting TGF- $\beta 1$-induced Smad2/3 activation [27, 28]. Also, TGF$\beta 1$ suppresses IFN- $\gamma$-induced STAT1-dependent gene transcription in epithelial cells through enhancement of protein inhibitor of activated STAT1 (PIAS1) [29]. The opposing roles of TGF- $\beta 1$ and IFN- $\gamma$ should be a topic of further investigation in the context of Stat $1^{-/}$susceptibility to rMWCNTs.

Others have shown that the same rMWCNTs used in the present study increase TGF- $\beta 1$ in fibrotic foci within the lungs of mice exposed by oropharyngeal aspiration and TGF- $\beta$ receptor- 1 (TGF- $\beta$ RI) has been implicated as a major regulator of MWCNT-induced fibrogenesis in mice exposed to rMWCNTs [30]. For example,
rMWCNTs induced TGF- $\beta$ RI in human lung fibroblasts in vitro and knock down or inhibition of TGF- $\beta R 1$ or knock down of Smad2 resulted in decreased collagen production $[22,30]$. We were unable to detect TGF- $\beta R I$ in the present study, but observed that TGF- $\beta$ RII levels were not changed by rMWCNT treatment or STAT1 deficiency. Nevertheless, it is possible that STAT1 could regulate levels of TGF- $\beta$ RI. In addition to the collagen synthetic pathways induced by TGF- $\beta 1$, it is also possible that inhibition of collagen-degrading proteases may be involved in the fibrogenic response to rMWCNTs.

Fibrogenesis stimulated by a foreign body insult (e.g., particles and fibers) is thought to be initiated at least in part by acute injury to epithelial cells. Increased epithelial proliferation marks an injury event where DNA synthesis and cell cycle progression are initiated as a homeostatic repair response, much like what is seen with chrysotile asbestos inhalation exposure [31]. In this study, we observed a significant increase in the proliferation of airway epithelial cells by BrdU uptake after exposure to rMWCNTs (Fig. 4). BrdU uptake at one-day was also induced by tMWCNTs but not to a significant extent. Furthermore, we observed that Stat $^{-1-}$ mice exhibited significantly greater airway epithelial proliferation compared to vehicle-treated or tMWCNT-treated Stat $^{-/-}$mice. BrdU uptake in the airway epithelium of 
rMWCNT-treated Stat ${ }^{-/-}$mice was twice that seen in rMWCNT-treated Stat $^{+/+}$mice, yet this difference was not statistically significant (Fig. 4). The increase in airway epithelial cell BrdU uptake could be mediated by growth factors (e.g., PDGF, EGF) produced by epithelial cells, macrophages, or other pulmonary cell types. We previously reported that primary Stat $^{-1-}$ MLFs have enhanced proliferative responses to PDGF or EGF in vitro [19]. Therefore, it is possible that airway epithelial cells from $\mathrm{Stat}^{-/-}$mice might have enhanced proliferative responses to growth factors in vivo.

We observed that both rMWCNTs and tMWCNTs produced granulomas, although rMWCNTs produced significantly larger granulomas than tMWCNTs (Fig. 3). Other studies have documented granuloma formation after MWCNT exposure [4-6, 20, 29, 32-34]. Granulomas centrally consist of epithelioid and multinucleated giant macrophages surrounded by activated lymphocytes, typically activated CD4+ T cells [35]. Granulomas resulting from MWCNT treatment have been found to contain CD3+ monocytes and CD4+ T cells, as well as increased levels of osteopontin (OPN) in the granulomatous foci in mouse lungs [36]. In our study, granuloma formation was generally independent of STAT1 as both Stat $^{-/-}$and Stat $^{+/+}$mice had a mean granuloma size that was not statistically different between genotypes. Moreover, OPN levels were similar between genotypes, albeit strongly induced by rMWCNTs (Additional file 4). However, two out of six Stat1 ${ }^{-/}$mice exposed to rMWCNTs had at least one exaggerated granuloma, although these "super-granulomas" were rare and did not contribute significantly to differences in granuloma size between genotypes (data not shown). Other investigators have reported that $S t a t 1^{-1-}$ mice infected with M. tuberculosis have larger granuloma development compared their infected Stat $^{+/+}$counterparts [37].

Mucociliary clearance is an innate immune response that removes inhaled particles and fibers from the lungs, yet excessive mucous cell metaplasia and mucus hypersecretion contributes to airway obstruction. Mucous cell metaplasia has been observed previously in mice exposed to rMWCNTs $[9,10]$. Induction of Th2 cytokines such as IL-4 and IL-13, activation of STAT6, and transcription of mucin genes (muc5ac and muc5b) contribute to mucin formation in airway epithelial cells [38]. We did not observe significant differences in IL-4 or IL13 mRNA levels between genotypes or treatment groups, although there was a trend for increased IL-4 mRNA in the lungs of Stat1 ${ }^{-/}$mice treated with rMWCNTs (Additional file 2). However, others have shown that rMWCNTs cause increased IL-13 mRNA levels and allergic airway inflammation in female mice after inhalation exposure [9]. In addition, Hussain et al. observed mucous cell metaplasia after 21 days post-exposure to tMWCNTs in female mice [39]. This contrasts to most other studies performed in male mice. Therefore, sex differences could explain the difference in mechanism of mucous cell metaplasia observed in this study. It is also conceivable that an IL-13-independent mechanism could mediate mucous cell metaplasia in response to rMWCNTs. For example, STAT6 activation can also occur through an alternative mechanism involving STING and TBK1 activation [40].

STAT1 is an IFN- $\gamma$ activated transcription factor driving the differentiation of naïve $\mathrm{T}$ cells to become Th1 cells. In the absence of a Th1 environment, there will more likely be a shift towards a Th2 response. In the present study, induction of a systemic Th2 immune response in Stat1 $^{-/-}$mice was evident by increased levels of serum IgE. Serum IgE levels were especially high in Stat $^{-/-}$mouse serum and increased greatly following treatment of Stat1 $^{-/-}$mice with rMWCNTs after 21 days (Fig. 6b). However, both Stat1 $^{+/+}$and Stat1 ${ }^{-/-}$mice exhibited increased mucous cell metaplasia with rMWCNT treatment but not tMWCNTs. The reason for a differential systemic allergic response yet similar allergic lung responses between $\operatorname{Stat}_{1}^{+/+}$and $\operatorname{Stat}^{1^{-/}}$remains to be elucidated.

In addition to genetic susceptibility, our study highlights the importance of nanotube rigidity. Physicochemical characteristics other than rigidity could also influence the allergic immune and fibrotic potential of MWCNTs. For example, length is an important determinant as intratracheal instillation of long, but not short, MWCNTs causes the formation of granulomas, upregulation of ECM protease inhibitors, increased collagens, and TGF- $\beta 1$ production in rats [21]. Thicker and longer MWCNTs induce the greatest DNA damage and induce transcriptional markers of fibrosis compared to thinner, shorter MWCNTs [34, 35]. Finally, differences in residual metal catalysts (Fe in rMWCNTs and $\mathrm{Ni}$ in tMWCNTs) could influence toxicity and disease outcome. Collectively, these studies along with our observations in the present work emphasize that multiple physicochemical characteristics should be considered in the design of MWCNTs to reduce or prevent future disease.

\section{Conclusions}

In summary, MWCNT rigidity plays a substantial role in pulmonary toxicity. Moreover, STAT1 is an important protective factor and plays a role in suppressing the fibrogenic response to rMWCNTs by inhibiting TGF- $\beta 1$ production, intracellular Smad2/3 phosphorylation, and collagen synthesis. Both rigidity and genetic susceptibility should be major considerations for risk assessment and development of MWCNTs. 


\section{Methods}

\section{MWCNT materials and preparation}

tMWCNTs were obtained from Helix Material Solutions Inc. (Richardson, TX). rMWCNTs (XRNI MWNT-7 05072001 K28) were obtained from Dale Porter at NIOSH and manufactured by Mitsui \& Co (Tokyo, Japan). Pluronic F-68 Solution (\#P5556) from Sigma (Saint Louis, MO) was diluted with DPBS to $0.1 \%$ and used to bring MWCNTs to a working concentration of $2 \mathrm{mg} / \mathrm{mL}$. MWCNTs were sonicated in a cup horn sonicator for $2 \mathrm{~min}$ and were also vortexed vigorously immediately prior to dosing mice $4 \mathrm{mg} / \mathrm{kg}$ via oropharyngeal aspiration.

\section{Rigidity measurements}

Measurements were taken as described in Method 3 by the International Standards Organization 11,888:2011 $[41,42]$. Ten transmission electron microscope (TEM) images of tMWCNTs and ten of rMWCNTs taken at 10000X were used to perform length measurements of each MWCNT directly from end to end (R) and along the axis $(L)$ of each tube per image; these lengths were measured using the Adobe Photoshop C5S ruler tool to convert pixels to $\mu \mathrm{m}$ and trace the imaged MWCNTs. These measurements were averaged into a bending ratio $\left(D_{b}\right)$ between the mean-squared end-to-end distance $\left\langle\mathrm{R}^{2}\right\rangle$ and squared contour length $\left(L^{2}\right)$ to determine the approximate static bending persistence length (SBPL) using the equations:

$$
\begin{aligned}
& \mathrm{D}_{\mathrm{b}}=<\mathrm{R}^{2}>/ L^{2} \\
& \mathrm{SBPL}=\left(\mathrm{D}_{\mathrm{b}}{ }^{*} L\right) / 2 .
\end{aligned}
$$

\section{Animal care}

Pathogen free 6-8 week old adult SV129 male Stat $1^{+/+}$ and Stat $^{-/-}$mice were purchased from Taconic Laboratories (Germantown, NY) and housed in an IACUC approved and AALAC-accredited animal facility. Animals were acclimated for two weeks prior to treatments. Animals were housed 1-5 per cage and fed water and LabDiet 5001 rodent diet ad libitum.

\section{Experimental design and collection of mouse samples}

The experimental design is illustrated in Fig. 2a. Stat $1^{+/+}$ and Stat $^{-/-}$mice were divided into 3 treatment groups (vehicle, tMWCNT, or rMWCNT) for one and 21 day sample collections. Mice were anesthetized with isoflurane and dosed with $4 \mathrm{mg} / \mathrm{kg}$ tMWCNTs $(n=6), 4 \mathrm{mg} / \mathrm{kg}$ rMWCNTs $(n=12)$, or equal volume pluronic vehicle $(n=18)$ via oropharyngeal aspiration. Half the mice from each treatment group were euthanized via intraperitoneal (i.p.) injection of pentobarbital (Vortech Pharmaceuticals, LTD, Dearborn, MI \#NDC 0298-9373-68) at one-day post-exposure and the rest at 21 days post-exposure. Serum was collected immediately and extracted from clotting factors using a BD (Franklin Lakes, NJ) microtainer SST. Two $0.5 \mathrm{~mL}$ aliquots of phosphate buffered saline (PBS) were instilled via intratracheal cannulation and retrieved to collect bronchoalveolar lavage fluid (BALF) for cytokine and cellular content. The left lobe of the lung was inflated and fixed for histology with neutral buffered formalin (Azer Scientific, Morgantown, PA \#NBF-4-G) and the right lobes were divided equally into RNAlater (Sigma \#R0901) for mRNA or snap frozen in liquid nitrogen for protein analysis. Small intestine, heart, spleen, brain, and liver samples were also collected for histology and mRNA analysis.

\section{Enzyme-linked immunosorbent assay (ELISA)}

BALF was analyzed using DuoSet ELISA kits (R \& D Systems, Inc., Minneapolis, MN) specific for mouse TGF- $\beta 1$ (DY1679), Osteopontin (OPN) (DY441), and IL-1 $\beta$ (DY401). Serum IgE was assayed using a BD Pharmingen ELISA kit (557,079, San Jose, CA). Sample concentrations in BALF or serum were derived from absorbance values and converted to concentration values based on standards provided with each kit.

\section{Cell counts}

Differential cell counts were obtained by Cytospin centrifugation of $100 \mu \mathrm{L}$ of BALF using a Single Cytology Funnel (Fisherbrand, Pittsburgh, PA, 10-354) onto a slide and once dry, stained with DiffQuik (Siemens, Munich, Germany, B4132-1A). Differential cell counts were taken by counting 500 cells per slide/animal to identify relative percentages of macrophages, neutrophils, eosinophils, and lymphocytes.

\section{Quantitative morphometry of lung granulomas}

Granulomas in lung sections stained with Masson's Trichrome were analyzed by light microscopy (Olympus BX40 microscope). A granuloma was defined as a multicellular focal formation consisting of monocytes, macrophages, fibroblasts, and epithelial cells surrounding a MWCNT aggregate. Some granulomas also contained neutrophils and eosinophils. Photomicroscopic images were analyzed using Adobe Photoshop CS5 to determine the area of each granuloma formation by using the lasso tool and converting pixels to $\mu \mathrm{m}$.

\section{Airway area to perimeter ratio}

An area to perimeter (AP) ratio method was used to quantitatively assess airway fibrosis as previously described [7, 11]. Briefly, light microscopic images of Masson's trichrome-stained airways were analyzed using Adobe Photoshop CS5; the lasso tool was used to outline the inside perimeter of the airway along the basal 
membrane of the airway epithelium and along the outside perimeter of the 'blue-stained' connective tissue surrounding the airway. The ratio of this inner to outer measurement circumference measurement is referred to as the area to perimeter ratio.

\section{Bromodeoxyuridine (BrdU) immunohistochemistry (IHC)}

Mice received an i.p. injection of $100 \mathrm{mg} / \mathrm{kg}$ BrdU in PBS one-hour prior to euthanasia with an i.p. injection of pentobarbital. Formalin-fixed, paraffin embedded blocks of lung or small intestine (positive control) were cut $5 \mu \mathrm{m}$ with a microtome and mounted on a positively charged slide and dried overnight. The sections were immunostained with anti-BrdU Pure (BD \#347580) followed by the Vectastain $\mathrm{ABC}$ kit (VectorLabs, Burlingame, $\mathrm{CA}$, \#PK-6102) and DAB buffer (BioGenex, San Ramon, CA, \#HK542-XAK) as described per manufacturer protocol. BrdU-positive brown-stained nuclei stand out from the hematoxalin counterstain. Photomicroscopic images were analyzed in Adobe Photoshop CS5 using the count tool to measure numbers of BrdU-positive epithelial cells associated with each airway. BrdU-positive cells were normalized for the total number of airway epithelial cells in each airway section. Data are the average percent of BrdU positive cells per airway per mouse in each treatment group.

\section{Mucin quantification}

Photomicroscopic images of Alcian Blue -Periodic Acid Schiff (AB-PAS) stained lung sections were analyzed using Image J software and the area of positive stained blue/purple mucin was quantified as previously described [11].

\section{RT-PCR}

Applied Biosystems high capacity cDNA reverse transcription kit (Fisher \#4368814) was used to create cDNA from the mRNA isolated from the right lung lobes using QuickRNA $^{\text {tw }}$ MiniPrep (Zymo Research, Irvine, CA, \#R1058) according to the manufacturer's instructions. The FastStart Universal Probe Master (Rox) (Roche, Basel, Switzerland, \#16881300) was then used to run Taqman qPCR on the Applied Biosystems OneStepPlus ${ }^{\text {Tw }}$ Real-Time PCR System Thermal Cycling Block (ABI, Foster City, CA, Cat\#4376598) to determine the comparative $C_{T}\left(\Delta \Delta C_{T}\right)$ fold change expression of IL-4, IL-13, PDGF-A, PDGF-B, Colla1, and Col1a2 normalized for $\beta 2$-microglobulin (B2M) as the endogenous control.

\section{Collagen analysis}

Snap frozen right cranial lung lobes were thawed and 10-50 mg of tissue was prepared for the Sircol Assay (Biocolor Ltd., Carrickfergus, UK, \#S1000). The tissues and samples were analyzed according to the manufacturer's instructions. Briefly, samples were sonicated for $6 \mathrm{~min}$ and then treated with Triton-X (Sigma \#T8787) overnight. These samples were combined with Sirius Red dye and collagen hydroxyproline residues pelleted by centrifugation at full speed. The pellet was then washed twice with 99.9\% cold denatured alcohol before resuspension in an alkali reagent. Absorbance was measured at $540 \mathrm{~nm}$ on a microplate reader to determine the concentration of collagen per lung. Samples were assayed in duplicate and collagen content was normalized to protein concentration of lung lysate and reported as $\mu \mathrm{g}$ of soluble collagen per $\mathrm{mg}$ of total protein. Collagen content in the lungs of mice was also measured by hydroxyproline assay according to the manufacturers' instructions (Sigma, St. Louis, MO).

\section{Immunoblotting}

Whole lung protein lysates were isolated from snap-frozen mouse left lung lobes and concentrations determined using the Pierce BCA Protein Assay Kit (ThermoFisher Scientific, Waltham, MA, \#23225). Samples were diluted, loaded onto a Novex ${ }^{\text {Tw }} 4-12 \%$ SDS-PAGE gel (Invitrogen, Carlsbad, CA, \#XP04122BOX), and separated by electrophoresis as described previously [43]. Briefly, samples were transferred to PVDF membranes, blocked, and incubated in primary antibody (1:1000 dilution). Rabbit polyclonal pSmad2/3 (\#8828), total Smad2/3, and $\beta$-actin (\#4967) primary antibodies as well as anti-rabbit (\#7074) secondary antibody were purchased from Cell Signaling Technology (Beverly, MA). Following primary antibody incubation, the membranes were washed and then incubated with horseradish peroxidase-conjugated secondary antibody (1:2500 dilution). Enhanced chemiluminescence (ECL) (ThermoFisher Scientific \#50-904-9326) was used to visualize immunoblot signals. Protein lysate was extracted from lung tissue of Stat $^{+/+}$mouse lungs after 21 day exposure to vehicle $(n=9)$, tMWCNT $(n=3)$, and rMWCNT $(n=6)$ and Stat $^{-1-}$ mouse lungs exposed to vehicle $(n=9)$, tMWCNT $(n=3)$, and rMWCNT $(n=6)$. To quantify all immunoblot signals, densitometry was performed as described previously using Adobe Photoshop CS5 [44].

\section{Statistics}

Statistical analysis of the data was performed using GraphPad Prism version 5.0 (GraphPad Software Inc.). A one-way ANOVA with a post hoc Tukey test was used to determine significance between samples. A two-way ANOVA was used with a Bonferroni post-test to compare between genotypes.

\section{Additional files}

Additional file 1: Physicochemical parameters of tangled ( $t$ ) and rigid ( $r$ ) multi-walled carbon nanotubes (MWCNTs). (PDF $31 \mathrm{~kb}$ )

Additional file 2: Interleukin-4 (IL-4) and IL-13 mRNA expression in Stat ${ }^{+/+}$ and $\mathrm{Stat}^{-1-}$ mouse lungs after exposure to tMWCNTs or rMWCNTs. A) Fold change in $\mathrm{L}-4 \mathrm{mRNA}$ at one and B) 21 days post-exposure. C) Fold change in 
IL-13 mRNA expression at one and D) 21 days post-exposure. Expression of mRNA normalized to $\beta 2$-microglobulin (B2M). (PDF $352 \mathrm{~kb}$ )

Additional file 3: Soluble collagen content measured from mouse lungs 21 days post-exposure. Average soluble collagen concentration per lung in each respective treatment after 21 days of exposure to control, tMWCNTs, or rMWCNTs normalized to protein content of sample. (PDF $314 \mathrm{~kb}$ )

Additional file 4: Osteopontin (OPN) protein levels in lungs from Stat $1^{+/+}$ and $\mathrm{Stat}_{1}{ }^{-1}$ mice after one and 21 days of exposure to tMWCNTs or rMWCNTs. A) OPN protein in BALF after one and B) 21 days exposure to vehicle, tMWCNTS, or rMWCNTs as measured by ELISA. $\left({ }^{*} p<0.05\right.$ or ${ }^{* *} p<0.001$ compared to control). (PDF $329 \mathrm{~kb}$ )

Additional file 5: Platelet derived growth factor (PDGF) -A and -B expression in $\mathrm{Stat}^{+/+}$and $\mathrm{Stat}_{1}{ }^{-/}$mouse lungs after exposure to tMWCNTs or rMWCNTs. A) Fold change in PDGF-A mRNA at one and B) 21 days post-exposure. C) Fold change in PDGF-B mRNA expression at one and D) 21 days post-exposure. Expression of mRNA normalized to B2M. (PDF $356 \mathrm{~kb}$ )

Additional file 6: Expression levels of collagen mRNAs determined via Taqman qRT-PCR of RNA isolated from mouse lungs 21 days post-exposure. A) Fold change in Col1a1 and B) Col1a2 mRNA expression after 21 days post-exposure. Expression of mRNA levels normalized to B2M. (PDF $137 \mathrm{~kb}$ )

\section{Abbreviations}

BALF: Bronchoalveolar lavage fluid; BrdU: Bromodeoxyuridine; CNTs: Carbon nanotubes; Db: Static bending ratio; ECM: Extracellular matrix; EGF: Endothelial growth factor; ELISA: Enzyme linked immunosorbent assay; ERK: Extracellular signal related kinase; IFN: Interferon; IgE: Immunoglobulin E; IL: Interleukin; MAD: Mothers against decapentaplegic protein (Drosophilia): MAPK: Mitogen activated protein kinase; MWCNTs: Multi-walled CNTs; OPA: Oropharyngeal aspiration; OPN: Osteopontin; PDGF-A: Platelet derived growth factor-A; PDGF-B: Platelet derived growth factor-B; rMWCNT: Rod-like MWCNT; SBPL: Static bending persistence length.; SMA: Small body size protein (Caenorhabditis elegans); STAT1: Signal transducer and activator of transcription-1; Stat ${ }^{-/-}$: STAT1 knockout; Stat ${ }^{+/+}$: Wild type for STAT1; TEM: Transmission electron microscope; TGF- $\beta$ RI: TGF- $\beta$ receptor I; TGF$\beta 1$ : Transforming growth factor- $\beta 1$; TGF- $\beta$ RII: TGF- $\beta$ receptor Il; Th1: type $1 \mathrm{~T}$ helper cell; Th2: type $2 \mathrm{~T}$ helper cell; tMWCNT: Tangled MWCNT

\section{Acknowledgments}

We thank Dr. Dale Porter at NIOSH for providing rMWCNTs (Mitsui-7), Professor II Je Yu at Hoseo University, South Korea for advice on the method for determining carbon nanotube bending ratio, and Dr. Debra Tokarz at NCSU College of Veterinary Medicine for advice on identity of inflammatory cell types in granulomas.

\section{Funding}

This work was supported by NIEHS R01ES020897 (JCB, GNP, KSD, MDI, ECN, KAS, AJT), and NIEHS Training Grant: T32 ES007046 (KSD, MDI). JCB was partially supported by NIEHS P30 ES025128.

\section{Availability of data and materials}

Not applicable.

\section{Authors' contributions}

Conception and design: KSD, JCB; Experimentation analysis and interpretation: KSD, AJT, MDI, KAS, EAT, ECD, GNP, JCB; Drafting the manuscript for important intellectual content: KSD, JCB. All authors read and approved the final manuscript.

\section{Ethics approval and consent to participate}

Not applicable.

\section{Consent for publication}

Not applicable.

\section{Competing interests}

The authors declare that they have no competing interests.

\section{Publisher's note}

Springer Nature remains neutral with regard to jurisdictional claims in published maps and institutional affiliations.

\section{Author details}

${ }^{1}$ Toxicology Program, Department of Biological Sciences, North Carolina State University, Campus Box 7633, Raleigh, NC 27695-7633, USA.

2Department of Chemical and Biomolecular Engineering, North Carolina State University, Raleigh, NC 27695, USA.

Received: 4 March 2017 Accepted: 7 July 2017

Published online: 17 July 2017

\section{References}

1. Donaldson K, Aitken R, Tran L, Stone V, Duffin R, Forrest G, et al. Carbon nanotubes: a review of their properties in relation to pulmonary toxicology and workplace safety. Toxicol Sci. 2006;92:5-22.

2. Seaton A, Tran L, Aitken R, Donaldson K. Nanoparticles, human health hazard and regulation. J R Soc Interface. 2010;7(Suppl 1):S119-29.

3. Donaldson K, Murphy FA, Duffin R, Poland C. Asbestos, carbon nanotubes and the pleural mesothelium: a review of the hypothesis regarding the role of long fibre retention in the parietal pleura, inflammation and mesothelioma. Part. Fibre Toxicol. 2010;7:5.

4. Muller J, Huaux F, Moreau N, Misson P, Heilier JF, Delos M, et al. Respiratory toxicity of multi-wall carbon nanotubes. Toxicol Appl Pharmacol. 2005;207:221-31.

5. Dong J, Porter DW, Batteli LA, Wolfarth MG, Richardson DL, Ma Q. Pathologic and molecular profiling of rapid onset fibrosis and inflammation induced by multiwalled carbon nanotubes. Arch Toxicol. 2015;89(4):621-33.

6. Mercer RR, Hubbs AF, Scabilloni JF, Wang L, Battelli L, Friend S, et al. Pulmonary fibrotic response to aspiration of multi-walled carbon nanotubes. Part Fibre Toxicol. 2011:8:21.

7. Ryman-Rasmussen JP, Cesta MF, Brody AR, Shipley-Phillips JK, Everitt J, Tewksbury EW, et al. Inhaled carbon nanotubes reach the subpleural tissue in mice. Nat Nanotechnol. 2009;4:747-51.

8. Mercer RR, Scabilloni JF, Hubbs AF, Wang L, Battelli L, McKinney W, et al. Extrapulmonary transport of MWCNT following inhalation exposure. Particle and Fibre Toxicology. 2013;10:38.

9. Rydman EM, Ilves M, Koivisto AJ, Kinaret PAS, Fortino V, Savinko TS, et al. Inhalation of rod-like carbon nanotubes causes unconventional allergic airway inflammation. Part. Fibre Toxicol. 2014;11:1-17.

10. Porter DW, Hubbs AF, Mercer RR, Wu N, Wolfarth MG, Sriram K, et al. Mouse pulmonary dose- and time course-responses induced by exposure to multiwalled carbon nanotubes. Toxicology. 2010;269:136-47.

11. Thompson EA, Sayers BC, Glista-Baker EE, Shipkowski KA, Ihrie MD, Duke KS, et al. Role of signal transducer and activator of transcription 1 in murine allergen-induced airway remodeling and exacerbation by carbon nanotubes. Am J Respir Cell Mol Biol. 2015;53:625-36.

12. Nagai H, Okazaki Y, Chew S, Misawa N, Yamashita Y, Akatsuka S, et al. Diameter and rigidity of multiwalled carbon nanotubes are critical factors in mesothelial injury and carcinogenesis. Proc National Acad Sci USA. 2011; 108(49):E1330-8.

13. Aaronson DS, Horvath CM. A road map for those who don't know JAK-STAT. Science. 2002:296:1653-5

14. Simon AR, Takahashi S, Severgnini M, Fanburg BL, Cochran BH. Role of the JAK-STAT pathway in PDGF-stimulated proliferation of human airway smooth muscle cells. Am J Physiol Lung Cell Mol Physiol. 2002;282:L1296-304.

15. Gorina R, Sanfeliu C, Galitó A, Messeguer A, Planas AM. Exposure of glia to pro-oxidant agents revealed selective Stat1 activation by $\mathrm{H}_{2} \mathrm{O} 2$ and Jak2-independent antioxidant features of the Jak2 inhibitor AG490. Glia. 2007;55:1313-24.

16. Horvath CM, Wen Z, Darnell JE. A STAT protein domain that determines DNA sequence recognition suggests a novel DNA-binding domain. Genes Dev. 1995;9:984-94.

17. Ramana CV, Gil MP, Han Y, Rasohoff RM, Schreiber RD, Stark GR. Stat1independent regulation of gene expression in response to INF- $\gamma$. Proc Natl Acad Sci. 2001:98:6674-9.

18. Bonner JC. Mesenchymal cell survival in airway and interstitial pulmonary fibrosis. Fibrogenesis Tissue Repair. 2010;3:15.

19. Walters DM, Antao-Menezes A, Ingram JL, Rice AB, Nyska A, Tani Y, et al. Susceptibility of signal transducer and activator of transcription-1-deficient mice to pulmonary fibrogenesis. Am J Pathol. 2005;167:1221-9. 
20. Barna BP, Judson MA, Thomassen MJ. Carbon nanotubes and chronic granulomatous disease. Nano. 2014;4:508-21.

21. Wang $P$, Nie $X$, Wang Y, Li Y, Ge C, Zhang L, et al. Multiwall carbon nanotubes mediate macrophage activation and promote pulmonary fibrosis through TGF- $\beta /$ smad signaling pathway. Small. 2013;9:3799-811.

22. Vietti G, Ibouraadaten S, Palmai-Pallag M, Yakoub Y, Bailly C, Fenoglio I, et al. Towards predicting the lung fibrogenic activity of nanomaterials: experimental validation of an in vitro fibroblast proliferation assay. Part. Fibre Toxicol. 2013;10:52.

23. Rabolli V, Lo Re S, Uwambayinema F, Yakoub Y, Lison D, Huaux F. Lung fibrosis induced by crystalline silica particles is uncoupled from lung inflammation in NMRI mice. Toxicol Lett. 2011;203(2):127-34.

24. Girtsman TA, Beamer CA, Wu N, Buford M, Holian A. IL-1R signalling is critical for regulation of multi-walled carbon nanotubes-induced acute lung inflammation in C57BI/6 mice. Nanotoxicology. 2014;8(1):17-27.

25. Dimco G, Knight RA, Latchman DS, Stephanou A. STAT1 interacts directly with cyclin D1/Cdk4 and mediates cell cycle arrest. Cell Cycle. 2010;9:4638-49.

26. WI J, Park O, Radaeva S, Gao B. STAT1 inhibits liver fibrosis in mice by inhibiting stellate cell proliferation and stimulating NK cell cytotoxicity. Hepatology. 2006;44:1441-51.

27. Ramana CV, Chatterjee-Kishore M, Nguyen H, Stark GR. Complex roles of Stat1 in regulating gene expression. Oncogene. 2000;19:2619-27.

28. Massaqué J, Ulloa L, Doody J. Inhibition of transforming growth factor-beta/SMAD signaling by the interferon-gamma/STAT pathway. Nature. 1999;397:710-3.

29. Reardon C, McKay DM. TGF-beta suppresses IFN-gamma-STAT1-dependent gene transcription by enhancing STAT1-PIAS1 interactions in epithelia but not monocytes/macrophages. J Immunol. 2007;178:4284-95.

30. Mishra A, Stueckle TA, Mercer RR, Derk R, Rojanasakul Y, Castranova V, et al. Identification of TGF- $\beta$ receptor-1 as a key regulator of carbon nanotubeinduced fibrogenesis. Am J Physiol Lung Cell Mol Physiol. 2015;309:821-33.

31. Coin PG, Osornio-Vargas AR, Roggli VL, Brody AR. Pulmonary fibrogenesis after three consecutive inhalation exposures to chrysotile asbestos. Am J Respir Crit Care Med. 1996;154:1511-9.

32. Cesta MF, Ryman-Rasmussen JP, Wallace DG, Masinde T, Hurlburt G, Taylor AJ, et al. Bacterial lipopolysaccharide enhances PDGF signaling and pulmonary fibrosis in rats exposed to carbon nanotubes. Am J Respir Cell Mol Biol. 2010;43:142-51.

33. Manke A, Luanpitpong S, Dong C, Wang L, He X, Battelli L, et al. Effect of fiber length on carbon nanotube-induced fibrogenesis. Int J Mol Sci. 2014; 15:7444-61.

34. Jaurand M-CF, Renier A, Daubriac J. Mesothelioma: do asbestos and carbon nanotubes pose the same health risk? Part Fibre Toxicol. 2009;6:16.

35. Rosas LE, Snider HM, Barbi J, Satoskar AA, Lugo-Villarino G, Keiser T, et al. Cutting edge: STAT1 and T-bet play distinct roles in determining outcome of visceral leishmaniasis caused by Leishmania donovani. J Immunol. 2006;177:22-5.

36. Huizar I, Malur A, Midgette YA, Kukoly C, Chen P, Ke PC, et al. Novel murine model of chronic granulomatous lung inflammation elicited by carbon nanotubes. Am J Respir Cell Mol Biol. 2011;45:858-66.

37. Sugawara I, Yamada H, Mizuno S. STAT1 knockout mice are highly susceptible to pulmonary mycobacterial infection. Tohoku J Exp Med. 2004; 202:41-50.

38. Thai P, Chen Y, Dolganov G, Wu R. Differential regulation of MUC5AC/ Muc5ac and hCLCA-1/mGob-5 expression in airway epithelium. Am J Respir Cell Mol Biol. 2005;33:523-30.

39. Hussain S, Ji Z, Taylor AJ, Degraff LM, George M, Tucker CJ, et al. Multiwalled carbon nanotube functionalization with high molecular weight hyaluronan significantly reduces pulmonary injury. ACS Nano. 2016;10:7675-88.

40. Chen H, Sun H, You F, Sun W, Zhou X, Chen L, et al. Activation of STAT6 by STING is critical for antiviral innate immunity. Cell. 2011;147:436-46.

41. ISO/TS. TECHNICAL SPECIFICATION ISO / TS Nanotechnologies Characterization of single-wall carbon nanotubes using. 2011.

42. Lee HS, Yun CH, Kim HM, Lee CJ. Persistence length of multiwalled carbon nanotubes with static bending. J Phys Chem C. 2007;111:18882-7.

43. Shipkowski KA, Taylor AJ, Thompson EA, Glista-Baker EE, Sayers BC, Messenger ZJ, et al. An allergic lung microenvironment suppresses carbon nanotube-induced inflammasome activation via STAT6-dependent inhibition of caspase-1. PLoS One. 2015;10:6.

44. Sayers BC, Taylor AJ, Glista-Baker EE, Shipley-Phillips JK, Dackor RT, Edin ML, et al. Role of cyclooxygenase-2 in exacerbation of allergen-induced airway remodeling by multiwalled carbon nanotubes. Am J Respir Cell Mol Biol. 2013;49:525-35.

\section{Submit your next manuscript to BioMed Central and we will help you at every step:}

- We accept pre-submission inquiries

- Our selector tool helps you to find the most relevant journal

- We provide round the clock customer support

- Convenient online submission

- Thorough peer review

- Inclusion in PubMed and all major indexing services

- Maximum visibility for your research

Submit your manuscript at www.biomedcentral.com/submit 